\title{
$2-2014$
}

\section{Amine- and Sulfide-sensing Copper(I) lodide Films}

James P. Killarney

Meaghan McKinnon

Caitlin Murphy

et al.

Robert D. Pike

William \& Mary, rdpike@wm.edu

Follow this and additional works at: https://scholarworks.wm.edu/aspubs

Part of the Chemistry Commons

\section{Recommended Citation}

Killarney, James P.; McKinnon, Meaghan; Murphy, Caitlin; al., et; and Pike, Robert D., Amine- and Sulfidesensing Copper(I) lodide Films (2014). Inorganic Chemistry Communications, 40, 18-21. https://doi.org/10.1016/j.inoche.2013.11.022

This Article is brought to you for free and open access by the Arts and Sciences at W\&M ScholarWorks. It has been accepted for inclusion in Arts \& Sciences Articles by an authorized administrator of W\&M ScholarWorks. For more information, please contact scholarworks@wm.edu. 


\section{Amine- and Sulfide-Sensing Copper(I) Iodide Films}

James P. Killarney, ${ }^{\mathrm{a}}$ Meaghan McKinnon, ${ }^{\mathrm{a}}$ Caitlin Murphy, ${ }^{\mathrm{a}}$ Kylie M. Henline, ${ }^{\mathrm{b}}$ Charles Wang, ${ }^{\mathrm{b}}$ Robert D. Pike ${ }^{* b}$ and Howard H. Patterson*a

${ }^{a}$ Department of Chemistry, University of Maine, Orono, ME 04469-5706. Fax: (207)581-1191; Tel: (207)5811178; E-mail: Howard_Patterson@umit.maine.edu

${ }^{\mathrm{b}}$ Department of Chemistry, College of William and Mary, Williamsburg, VA 23187-8795. Fax: (757)221-2715;

Tel: (757)221-2555; E-mail: rdpike@wm.edu

Corresponding Author: Robert D. Pike

Department of Chemistry

College of William and Mary

Williamsburg, VA 23187-8795.

telephone: 757-221-2555

FAX: 757-221-2715

email: rdpike@wm.edu

Keywords: Copper Iodide, Luminescence, Sensing, Volatile Organic Compounds, Films, Photophysics 
Abstract: Copper(I) iodide films were cast onto glass from solution. The CuI films absorb vapor-phase amine and sulfide molecules, producing a range of photoluminescent emission colors. Spectroscopic data suggest the presence of low energy $\mathrm{CuI}$ cluster-centered transitions.

Real-time sensing of amine and sulfide pollutants in the environment is a matter of great importance [1]. These compounds are commonly found as contaminants in water [2], air [3], and food [4]. Although a multitude of sensor strategies have emerged in recent years, the plethora of relevant compounds provides on-going motivation for the discovery of new rapid, in situ sensing techniques. One real-time sensing strategy involves the spontaneous formation of photoemissive adducts on an inorganic or metal-organic substrate (Fig. 1) [5]. The unexposed detector film should be dark under UV irradiation and become emissive only after exposure to a volatile organic compound (VOC) as depicted in Fig. 1. Irradiation is not necessary for adsorption of the VOC, merely to visualize the product response. For such a device to be viable, the inorganic substrate must be cast as a film; in addition, the response to VOCs should ideally be sensitive, rapid, discriminating, and reversible [1].

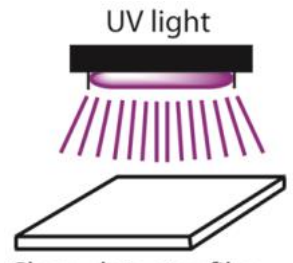

Clean detector film

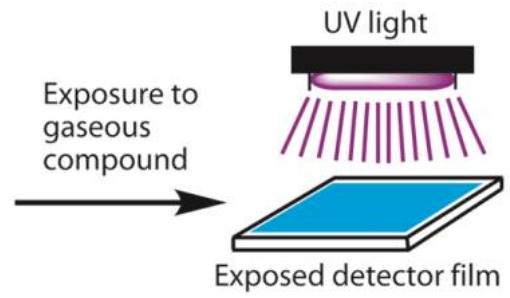

Figure 1. Design of potential luminescence VOC detector. as suggested in Fig. 1. We have shown that inexpensive and stable salts, such as $\mathrm{CuCN}$ [6], $\mathrm{CuSCN}$ [7], and $\mathrm{CuI}$ [8] spontaneously react with amines and other nucleophiles to make weakly-bound complexes that often show photoluminescence. The photophysics of the CuI-amine cubane and related clusters has been studied experimentally and computationally by Ford and others [8-10]. The results have revealed a variety of photophysical processes, including metal-centered (MC) and cluster-centered (CC) transitions which, although modulated by the amine, do not require amine acceptor orbitals (such as $\pi^{*}$ ). Although the vapochromic behavior of the $\mathrm{CuI}$ system has been noted [11], no research has yet demonstrated the facile casting and use of $\mathrm{CuI}$ films as viable VOC sensors. The objective of the current study is the development of $\mathrm{CuI}$ film surfaces for real-time 
photoluminescence detection of amine and sulfide vapors in the environment. It was anticipated that $\mathrm{CuI}$ films cast onto glass would enable us to exploit the facile formation and the known photoluminescence behavior of CuI-nucleophile adducts, offering facile visual detection of nucleophilic VOCs. Being a soft $\mathrm{d}^{10}$ Lewis acid, $\mathrm{Cu}(\mathrm{I})$ is not especially subject to coordination of water or formation of surface oxide. Furthermore, it is indefinitely stable in air.

$\mathrm{CuI}$ films were cast by evaporation of $100 \mathrm{mM} \mathrm{CuI} / \mathrm{CH}_{3} \mathrm{CN}$ solution on clean microscope cover glasses. The $\mathrm{CuI} / \mathrm{glass}$ films were exposed for 5-15 $\mathrm{min}$. to saturated atmospheres of amine or sulfide vapors in sealed containers. Steady-state photoluminescence spectra of the CuI/glass films were measured immediately after exposure at both ambient and liquid nitrogen temperatures. Scanning electron microscopy (Fig. 2) and optical microscopy (Fig. 2, Supporting Information) of unexposed and pyridine (Py) exposed CuI films showed film thicknesses of approximately $1 \mu \mathrm{m}$, and nearly continuous film coverage. As seen in Fig. 2, there is a difference in CuI surface morphology before and after exposure to Py vapor. Some degree of crystallinity is lost, but more complete coverage of the glass is realized, presumably due to recrystallization upon CuI-Py binding. Powder X-ray diffraction (PXRD) of fresh films confirmed the expected cubic $\gamma$-CuI phase (see Fig. 3). After Py exposure PXRD revealed the formation of an additional phase corresponding to the Py adduct (Fig. 3). 

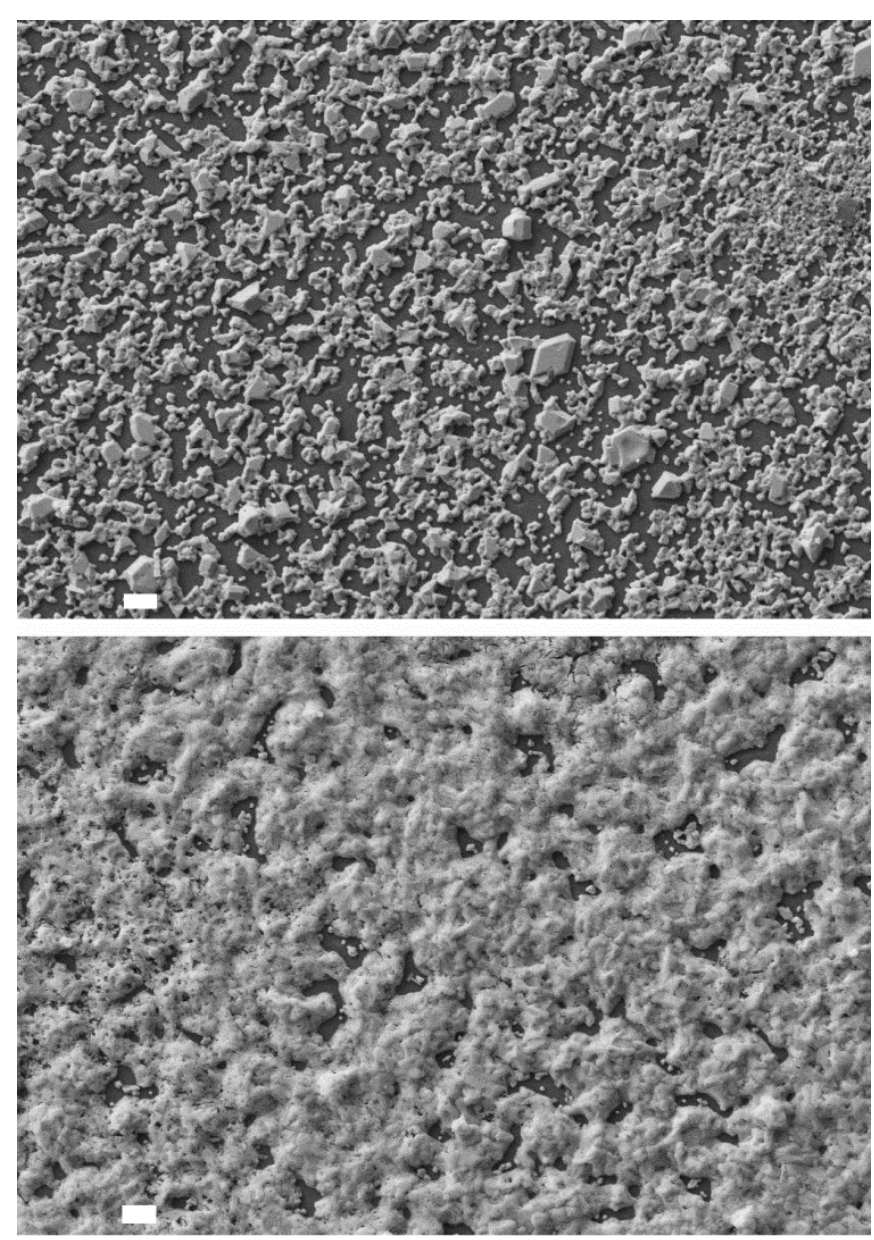

Figure 2. Scanning electron micrograph of unexposed (top) and pyridine-exposed (bottom) CuI film/glass sample $($ scale bar $=2 \mu \mathrm{m})$

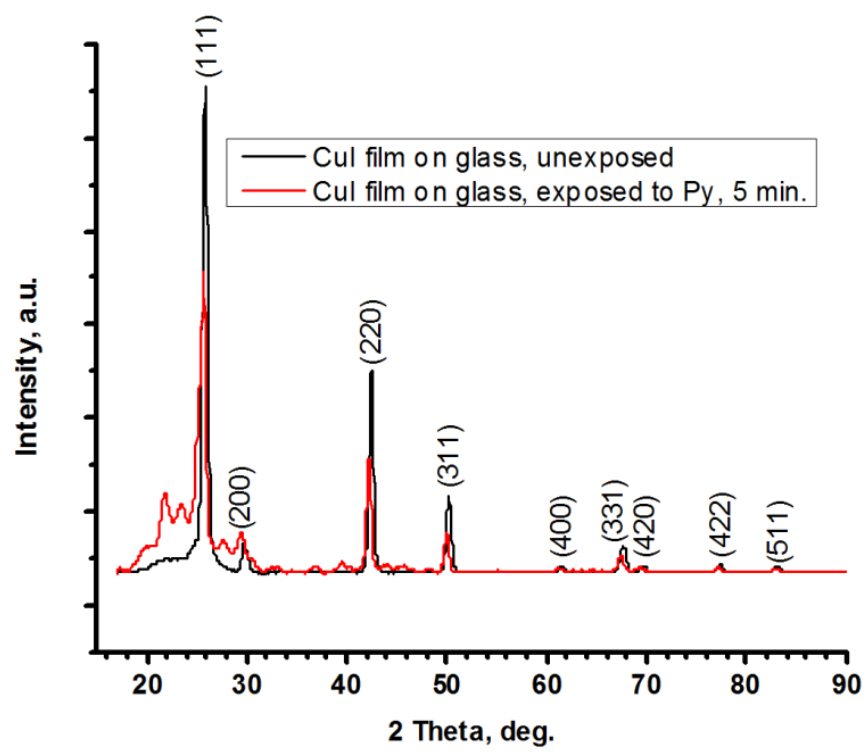


Figure 3. Powder diffraction trace of $\mathrm{CuI}$ film on glass before and after $5 \mathrm{~min}$. pyridine (Py) exposure. Indexed peaks for $\gamma-\mathrm{CuI}$ noted.

The luminescence activity of the exposed films was measured under ambient or reduced temperature conditions (see Fig. S3-S7). The unexposed CuI film on glass displayed a sharp narrow emission peak at $414 \mathrm{~nm}$ with a corresponding excitation peak at $390 \mathrm{~nm}$. This emission has been ascribed to the exciton band gap recombination of $\gamma-\mathrm{CuI}$ crystals [12]. This peak yields a very faint purple emission which remains detectable upon vapor exposure, but is no longer visible to the eye. A wide range of luminescence behavior is observed when the CuI films are exposed to amine vapors, as seen in Fig. 4. Table 1 displays the maximum excitation and emission energy and Stokes shift at ambient and liquid nitrogen temperatures for select amine and sulfide compounds. Maximum excitation of emissive adducts occurs in the UV (277-357 nm), varying fairly widely. Emission wavelength varied from blue to orange and was often distinctive even for chemically similar VOCs, demonstrating the potential selectivity of $\mathrm{CuI}$ detection. Aromatic amines tended to have higher emission energies than aliphatic amines or sulfides. Blue-shifts were noted for Py when substituted as various isomers of MePy, BrPy, and ClPy. Overall, emission maxima ranged from $447 \mathrm{~nm}$ (3-BrPy) to $620 \mathrm{~nm}$ (tetrahydrothiophene, THT) with relatively large Stokes shifts occurring in all cases. It was noteworthy that the 2-MePy, morpholine (Morph), and THT adducts showed pairs of emission peaks at room temperature.

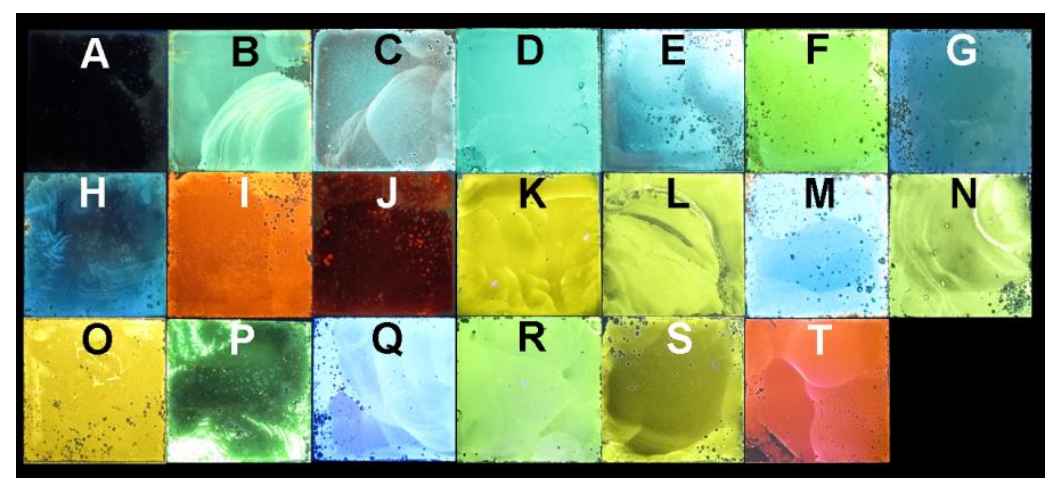

Figure 4. Previously VOC-exposed CuI films on glass placed under 365 nm irradiation. A, no exposure, B, Py; C, 2-MePy; D, 3-MePy; E, 4-MePy; F, 2-BrPy; G, 3-ClPy; H, 3-BrPy; I, 2-PhPy; J, 4-AcPy; K, Pipd; L, N-MePipd;

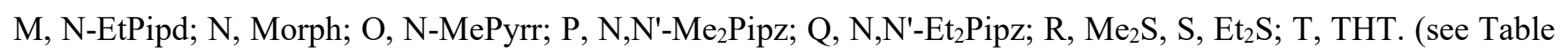
1 for abbreviation key.) 
Table 1. CuI-Adduct Luminescence Results

\begin{tabular}{|c|c|c|c|c|c|c|}
\hline \multirow[b]{2}{*}{ Adduct $^{\mathrm{a}}$} & \multicolumn{2}{|c|}{298 K Data } & \multirow[b]{2}{*}{ Stokes, $\mathrm{cm}^{-1}$} & \multicolumn{2}{|r|}{77 K Data } & \multirow[b]{2}{*}{ Stokes, $\mathrm{cm}^{-1}$} \\
\hline & $\operatorname{Ex} \lambda, \mathrm{nm}$ & $\operatorname{Em} \lambda, \mathrm{nm}$ & & $\mathrm{Ex} \lambda, \mathrm{nm}$ & $\operatorname{Em} \lambda, \mathrm{nm}$ & \\
\hline $\mathrm{Py}$ & 344 & 552 & 11000 & 365 & 500 & 7400 \\
\hline 2-MePy & 347,308 & 488,575 & 8390,15100 & - & - & - \\
\hline 3-МePy & 357 & 491 & 7980 & 320,360 & 463,497 & 9660,7660 \\
\hline 4-МеРy & 336 & 482 & 9020 & - & - & - \\
\hline 2-BrPy & 300 & 451 & 11200 & - & - & - \\
\hline 3-ClPy & 330 & 460 & 8560 & 316 & 461 & 9950 \\
\hline 3-BrPy & 325 & 447 & 8400 & - & - & - \\
\hline 2-PhPy & 277 & 495 & 15900 & - & - & - \\
\hline 4-AcPy & 327 & 594 & 13700 & 422 & 588 & 6690 \\
\hline Pipd & 322 & 586 & 14000 & 311 & 593 & 15300 \\
\hline MePipd & 305 & 553 & 14700 & - & - & - \\
\hline EtPipd & 312 & 472 & 10900 & - & - & - \\
\hline Morph & 305,337 & 414,615 & $8630, \quad 13400$ & 278,334 & 506,660 & 16800,14800 \\
\hline MePyrr & 324 & 584 & 13700 & - & - & - \\
\hline $\mathrm{Me}_{2} \mathrm{Pipz}$ & 308 & 532 & 13700 & - & - & - \\
\hline $\mathrm{Et}_{2} \mathrm{Pipz}$ & 308 & 442 & 9840 & - & - & - \\
\hline $\mathrm{Me}_{2} \mathrm{~S}$ & 308 & 546 & 14200 & - & - & - \\
\hline $\mathrm{Et}_{2} \mathrm{~S}$ & 326 & 590 & 13700 & - & - & - \\
\hline THT & 336 & 530,620 & 10900,13600 & 330 & 582 & 13100 \\
\hline
\end{tabular}

${ }^{a} \mathrm{Py}=$ pyridine, Ac $=$ acetyl, Pipd $=$ piperidine, Morph $=$ morpholine, Pyrr $=$ pyrrolidine, Pipz $=$ piperazine, THT $=$ tetrahydrothiophene. Aliphatic amines substituted at $\mathrm{N}$ position.

In general, small thermochromic shifts were seen between room temperature and $77 \mathrm{~K}$ luminescence experiments. A second, higher energy peak appeared for the 3-MePy adduct. Both Morph adduct peaks redshifted at $77 \mathrm{~K}$. THT exhibited interesting behavior, displaying blue-green and orange emission at room temperature, and only a strong green-yellow peak at $77 \mathrm{~K}$. Variable temperature excitation and emission spectra for 3-MePy and THT are shown in Fig. 5.

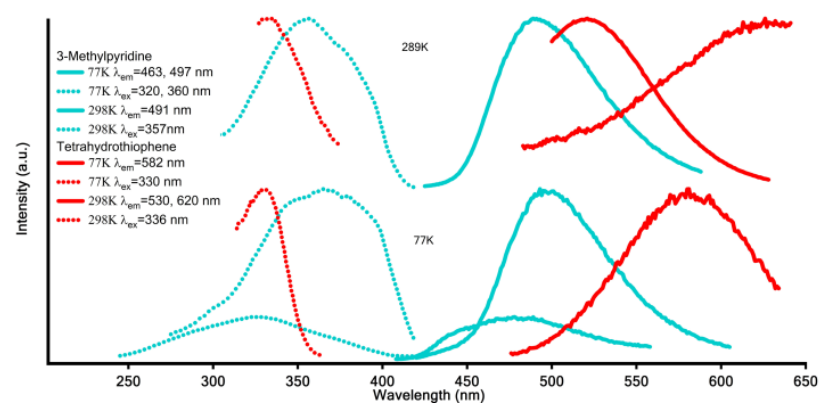

Figure 5. Ambient $(298 \mathrm{~K})$ and liquid nitrogen $(77 \mathrm{~K})$ temperature excitation and emission spectra of 3-MePy and THT. 
In order to understand the photophysical behavior of CuI-nucleophile (CuI-L) films, structural models for the adducted $\mathrm{CuI}$ surface must be considered. The most relevant models are the L-coordinated cubane tetramer $\left(\mathrm{Cu}_{4} \mathrm{I}_{4} \mathrm{~L}_{4}\right)$ and stair step polymer $\left(\mathrm{Cu}_{n} \mathrm{I}_{n} \mathrm{~L}_{n}\right)$, see Chart 1. Both polymorphs have been found for certain L (e.g. Py), and both are emissive; however, $\mathrm{Cu}_{4} \mathrm{I}_{4} \mathrm{~L}_{4}$ has been more widely studied ( $\mathrm{L}=$ amines, sulfides, phosphines) [8-10]. Two emission bands have been identified: a high energy (HE) and low energy (LE) band. The HE band has been ascribed to halide to ligand charge transfer $\left({ }^{3} \mathrm{XLCT}\right)$ transition having a ca. $90 \%$ I-based HOMO and $\pi *$ LUMO. The HE band is seen only when L has $\pi^{*}$ acceptor orbitals; it shows relatively small Stokes shifts and is thermochromic. The LE emission band is seen regardless of ligand type, shows very little change in emission with temperature, and has a large Stokes shift. The LE band has been assigned to a ${ }^{3} \mathrm{CC}$ transition of the type $\mathrm{I}_{4} \rightarrow$ $\mathrm{Cu}_{4}$ in which increased $\mathrm{Cu}-\mathrm{Cu}$ excited state bonding distorts the cluster. This reorganization produces the large Stokes shift.

As is evident from Chart 1 , the presumptive arrangement of $\mathrm{L}$ bonded to surface $\mathrm{Cu}(\mathrm{I})$ sites on $\gamma$-CuI must be very different from that of the cubane $\mathrm{Cu}_{4} \mathrm{I}_{4} \mathrm{~L}_{4}$ or stair step $\mathrm{Cu}_{n} \mathrm{I}_{n} \mathrm{~L}_{n}$. Nevertheless, it is reasonable to expect that the surface $\mathrm{Cu}$ atoms are bonded to three networked I atoms, as well as to $\mathrm{L}$. The resulting clusters are larger than $\mathrm{Cu}_{4} \mathrm{I}_{4}$, and thus are apt to exhibit even more facile $\mathrm{CC}$ transitions.

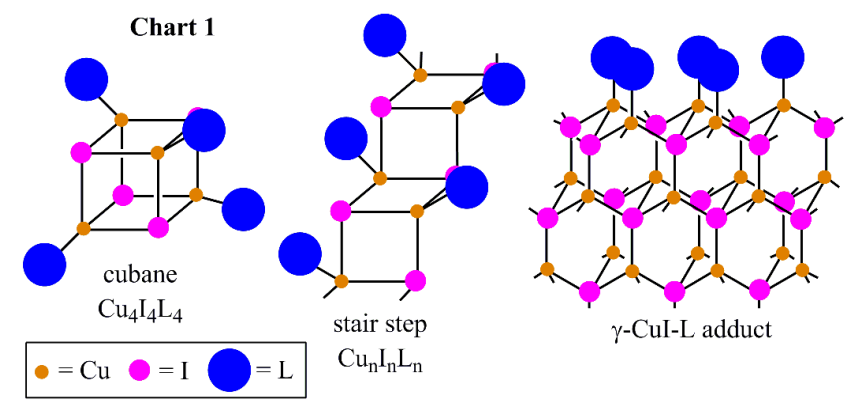

The emissive behavior of the compounds listed in Table 1 appears to be consistent with the LE band noted for $\mathrm{Cu}_{4} \mathrm{I}_{4} \mathrm{~L}_{4}$. Firstly, emission is observed for both aliphatic and aromatic ligands. Secondly, Stokes shifts are uniformly large for all ligands. And thirdly, emission energies show almost no thermochromism between 77 $\mathrm{K}$ and room temperature. Therefore, we hypothesize that emission from the $\mathrm{CuI}$ nucleophile-adducts arise from CC transitions. Nevertheless, a weak temperature-dependent HE peak was noted for 2- and 3-MePy, possibly representing the ${ }^{3} \mathrm{XLCT}$ noted for the cubane species. Of interest in the current data is the strong ligand 
dependence of emission energy. This suggests that the donor orbital of the amine or sulfide ligands exerts a substantial effect on the cluster HOMO and/or LUMO energy. Computational studies aimed at understanding this effect are underway.

In prior work [8], we reported that $\mathrm{N}, \mathrm{N}$ '-dimethylpiperazine $\left(\mathrm{Me}_{2} \mathrm{Pipz}\right)$ forms a linked 3D network of $\mathrm{Cu}_{4} \mathrm{I}_{4}$ cubane units. Like other $\left(\mathrm{Cu}_{4} \mathrm{I}_{4}\right)(\mathrm{LL})_{2}$ networks $(\mathrm{LL}=$ bridging diamine or bis(sulfide)) [13,14], $\left(\mathrm{Cu}_{4} \mathrm{I}_{4}\right)\left(\mathrm{Me}_{2} \mathrm{Pipz}\right)_{2}$ shows a relatively low energy and large Stokes shifted emission $(\lambda=525 \mathrm{~nm}$, Stokes $=12100$ $\left.\mathrm{cm}^{-1}\right)$. On the other hand, the CuI-Et 2 Pipz network consists of chains of Et ${ }_{2}$ Pipz-linked 3-coordinate $\mathrm{Cu}_{2} \mathrm{I}_{2} \mathrm{dimers}_{\text {, }}$ and emits in the blue $\left(\lambda=444 \mathrm{~nm}\right.$, Stokes $\left.=7780 \mathrm{~cm}^{-1}\right)$ [8]. Similar distinction between N-methyl (longer $\lambda$, higher Stokes) and N-ethyl (shorter $\lambda$, lower Stokes) was observed in the CuI film adducts for both the piperazines and piperidines. These results further support the notion that the ligands exert significant structural influence upon the cluster center, much as they do in isolated $\mathrm{Cu}_{\mathrm{n}} \mathrm{I}_{\mathrm{n}}$ clusters.

In summary, we have reported that $\mathrm{CuI}$ films cast onto a glass surface can act as vapochromic sensors for amine and sulfide VOCs (L). Because of the distinctive luminescence emission of the CuI-L adducts, CuI films show potential as environmental sensors. Photophysical analysis of the CuI-L adducts show behavior related to that of the known $\mathrm{Cu}_{4} \mathrm{I}_{4} \mathrm{~L}_{4}$ clusters. Quantitative studies of response factors versus VOC partial pressures are ongoing.

Supporting information available: (1) Visible light photograph and photomicrograph of CuI/glass film and (2) luminescence spectra for exposed film samples.

\section{Acknowledgements}

We gratefully acknowledge the National Science Foundation (CHE-0848109, RDP), (CHE-0351877, HHP), and the Virginia Space Grant Consortium (student awards to CW and KMH). James Killarney was funded by STAR Fellowship Assistance Agreement no. FP917137 awarded by the U.S. Environmental Protection Agency (EPA).

\section{References}

[1] (a) J. H. Sohn, R. Stuetz and M. Atzeni, in Chemical Sensors: Properties, Performance, and Applications, ed. R. V. Harrison, Nova Science: Hauppauge NY, 2010, pp 147-168; (b) D. James, S. M. Scott, Z. Ali and W. T. O'Hare, Microchim. Acta, 2005, 149, 1; (c) R. A. Potyrailo, C. Surman, N. Nagraj and A. 
Burns, Chem. Rev., 2011, 111, 7215; (d) H. H. Qazi, A. B. bin Mohammad and M. Akram, Sensors, $2012,12,16523$.

[2] (a) W. A. Mitch, J. O. Sharp, R. R. Trussell, R. L. Valentine, L. Alvarez-Cohen, D. L. Sedlak, Env. Eng. Sci., 2003, 20, 389; (b) B. Jurado-Sanchez, E. Ballesteros, M. Gallego, Water Res., 2012, 46, 4543.

[3] G. Palmiotto, G. Pieraccini, G. Moneti, P. Dolara, Chemosphere, 2001, 43, 355.

[4] A. R. Shalaby, Food Res. Int., 1996, 29, 675.

[5] (a) O. S. Wenger, Chem. Rev., 2013, 113, 5, 3686; (b) S. Su, W. Wu, J. Gao, J. Lu and C. Fan, J. Mater. Chem., 2012, 22, 18101; (c) H. Ma, R. Gao, D. Yan, J. Zhao, M. Wei, J. Mater. Chem. C, 2013, 1, 4128; (d) W. Li, D. Yan, R. Gao, J. Lu, M. Wei, X. Duan, J. Nanomater., 2013, 1; (e) C. Tan, Q. Wang, L. Ma, Photochem. Photobiol., 2010, 86, 1191.

[6] (a) T. A. Tronic, K. E. deKrafft, M. J. Lim, A. N. Ley, R. D. Pike, Inorg. Chem. 2007, 46, 8897; (b) R. D. Pike, K. E. deKrafft, A. N. Ley, T. A. Tronic, Chem. Commun. 2007, 3732; (c) M. J. Lim, C. A. Murray, T. A. Tronic, K. E. deKrafft, A. N. Ley, J. C. deButts, R. D. Pike, H. Lu, H. H. Patterson, Inorg. Chem. 2008, 47, 6931; (d) A. N. Ley, L. E. Dunaway, T. P. Brewster, M. D. Dembo, T. D. Harris, F. BarilRobert, X. Li, H. N. Patterson and R. D. Pike, Chem. Commun. 2010, 46, 4565; (e) M. D. Dembo, L. E. Dunaway, J. S. Jones, E. A. Lepekhina, S. M. McCullough, J. L. Ming, X. Li, F. Baril-Robert, H. H. Patterson, C. A. Bayse and R. D. Pike, Inorg. Chim. Acta 2010, 364, 102.

[7] K. M. Miller, S. M. McCullough, E. A. Lepekhina, I. J. Thibau and R. D. Pike, Inorg. Chem. 2011, 50, 7239.

[8] J. P. Safko, J. E. Kuperstock, S. M. McCullough, A. M. Noviello, X. Li, J. P. Killarney, C. Murphy, H. H. Patterson, C. A. Bayse and R. D. Pike, Dalton Trans., 2012, 41, 11663.

[9] (a) P. C. Ford, E. Cariati and J. Bourassa, Chem. Rev., 1999, 99, 3625; (b) M. Vitale and P. C. Ford, Coord. Chem. Rev., 2001, 219-221, 3; (d) P. Aslanidis, P. J. Cox, S. Divanidis and A. C. Tsipis, Inorg. Chem., 2002, 41, 6875; (e) H. Araki, K. Tsuge, Y. Sasaki, S. Ishizaka and N. Kitamura, Inorg. Chem., 2005, 44, 9667; (f) S. Perruchas, C. Tard, X. F. Le Goff, A. Fargues, A. Garcia, S. Kahlal, J.-Y. Saillard, T. Gacoin and J.-P. Boilot, Inorg. Chem., 2011, 50, 10682; (g) Z. Liu, P. I. Djurovich, M. T. Whited and M. E. Thompson, Inorg. Chem., 2012, 51, 230.

[10] (a) M. Vitale, C. K. Ryu, W. E. Palke and P. C. Ford, Inorg. Chem., 1994, 33, 561; (b) A. Vega and J.-Y. Saillard, Inorg. Chem., 2004, 43, 4012-4018; (c) F. De Angelis, S. Fantacci, A. Sgamellotti, E. Cariati, R. Ugo and P. C. Ford, Inorg. Chem., 2006, 45, 10576.

[11] (a) H. D. Hardt and A. Pierre, Z. Znorg. Allg. Chem., 1973, 402, 107; (b) E. Cariati, X. Bu and P. C. Ford, Chem. Mater., 2000, 12, 3385.

[12] H. Kang, R. Liu, K. Chen, Y. Zheng and Z. Xu, Electrochim. Acta, 2010, 55, 8121.

[13] (a) T. H. Kim, Y. W. Shin, J. H. Jung, J. S. Kim and J. Kim, Angew. Chem., Int. Ed., 2008, 47, 685; (b) T. Li and S.-W. Du, J. Cluster Sci., 2008, 19, 323-330; (c) M. Knorr, F. Guyon, A. Khatyr, C. Daschlein, C. Strohmann, S. M. Aly, A. S. Abd-El-Aziz, D. Fortin and P. D. Harvey, Dalton Trans., 2009, 948; (d) L.-L. Li, H.-X. Li, Z.-G. Ren, D. Liu, Y. Chen, Y. Zhang and J.-P. Lang, Dalton Trans., 2009, 8567; (e) X. Chai, S. Zhang, Y. Chen, Y. Sun, H. Zhang and X. Xu, Inorg. Chem. Commun., 2010, 13, 240; (f) (a) M. Knorr, F. Guyon, M. M. Kubicki, Y. Rousselin, S. M. Aly and P. D. Harvey, New J. Chem., 2011, 35, 1184.

[14] (a) M. Bi, G. Li, J. Hua, X. Liu, Y. Hu, Z. Shi and S. Feng, CrystEngComm, 2007, 9, 984; (b) M. Bi, G. Li, Y. Zou, Z. Shi and S. Feng, Inorg. Chem., 2007, 46, 604; (c) M. Bi, G. Li, J. Hua, Y. Liu, X. Liu, Y. Hu, Z. Shi and S. Feng, Cryst. Growth Des., 2007, 7, 2066-2070. (d) D. Braga, L. Maini, P. P. Mazzeo and B. Ventura, Chem. Eur. J., 2010, 16, 1553-1559. (e) Y. Zhang, T. Wu, R. Liu, T. Dou, X. Bu and P. Feng, Cryst. Growth Des., 2010, 10, 2047-2049. (f) D. Braga, F. Grepioni, L. Maini, P. P. Mazzeo and B. Ventura, New J. Chem., 2011, 35, 339. 